\title{
PEMBERDAYAAN ANAK YATIM MELALUI PENDAYAGUNAAN DANA ZAKAT, INFAQ, DAN SHADAQAH PADA LEMBAGA AMIL ZAKAT YATIM MANDIRI SURABAYA(1)
}

\author{
Andik Eko Siswanto \\ Mahasiswa Program Studi S1 Ekonomi Islam-Fakultas Ekonomi dan Bisnis-Universitas Airlangga \\ Email : andik.eko-12@feb.unair.ac.id \\ Sunan Fanani \\ Departemen Ekonomi Syariah-Fakultas Ekonomi dan Bisnis-Universitas Airlangga \\ Email : Sunan-f@feb.unair.ac.id
}

\begin{abstract}
:
The aims of this research is to find out the role of utilizing zakat, infaq and shadaqa on the empowerment of orphans in amil zakah institution of Yatim Mandiri Surabaya. The research method used in this research is descriptive qualitative with the case study method. In collecting the data, in-depth interview and direct observations had been done on the informants. Journals, text books, and other literatures are also used for the secondary data. This research found out that the utilization of zakat, infaq and shadaqa fund had a role in empowering the orphans through Mandiri Entrepreneur Center (MEC) program. The empowerment given on the orphans are in the form of education and entrepreneurship training while living in a dormitory. The development of this empowerment can be seen clearly with enhancements in academic independence, religion independence and economic independence.
\end{abstract}

Keywords: Utilization of Zakat Infaq Shadaqa, Empowerment, Orphans, Mandiri Enterpreneur Center (MEC)

\section{I.PENDAHULUAN}

Indonesia adalah negara yang memiliki jumlah penduduk 259.940.857, dengan $87 \%$ dari jumlah penduduknya adalah beragama Islam yaitu sebesar 204.867.000 jiwa, hal tersebut menunjukan bahwa Indonesia adalah Negara dengan populasi umat Islam terbesar di dunia (Badan Pusat Statisti, 2010). Dengan penduduk mayoritas beragaman Islam, tidak dapat terlepas dari perekonomian Islam.

Dengan kapasitas penduduk yang besar maka Indonesia memiliki banyak sumber daya manusia. Dengan potensi yang dimiliki negara Indonesia tersebut, maka kesejahteran masyarakat haruslah terjamin. Terutama dengan adanya zakat sebagai salah satu bentuk pendapatan Negara. Menurut penelitian Pusat Bahasa (1) Jurnal ini merupakan bagian dari Andik Eko Siswanto, NIM: 041211431165, yang diuji pada tanggal 26 Januari 2017 dan Budaya UIN syarif Hidayatullah, potensi dana zakat, infaq, dan shadaqah ketika dalam bentuk uang tunai kira-kira mencapai 14,2 triliun rupiah, dan ketika dalam bentuk barang adalah 5,1 triliun rupiah setiap tahun. Zakat adalah ibadah maaliyah ijtima'iyyah yang memiliki peran sangat penting, strategis, dan menentukan, baik dilihat dari sisi ajaran islam ataupun dilihat dari sisi pembangunan kesejahteraan umat. Zakat dalam tinjauan suatu hukum islam sebagian besar dikaitkan dengan kewajiban sholat. Salah satu ayat AlQur'an yang mensejajarkan sholat ada dalam surat Al-Baqarah ayat 43 yang berbunyi:

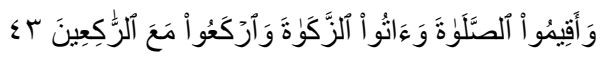


Siswanto, et al/Jurnal Ekonomi Syariah Teori dan Terapan Vol. 4 No. 9 September 2017: 698-712; PERAN PENDAYAGUNAAN ZAKAT, INFAQ, DAN SHADAQAH (ZIS) DALAM PEMBERDAYAAN ANAK YATIM (PURNA ASUH) PADA LEMBAGA AMIL ZAKAT YATIM MANDIRI SURABAYA

Artinya: "Dan dirikanlah shalat, tunaikanlah zakat dan ruku'lah beserta orang-orang yang ruku'." (QS, 2 Al-Baqarah:43) "Yang dimaksud ialah: shalat berjama'ahlah dan dapat pula diartikan: tunduklah kepada perintah-perintah Allah bersamasama orang-orang yang tunduk."

Pendayagunaan dana zakat adalah bentuk pemanfaatan sumber dana zakat yang ditujukan untuk mencapai kesejahteraan dan kemaslahatan bagi masyarakat (umat). Pendayagunaan dana zakat itu sendiri diarahkan pada tujuan pemberdaayaan melalui berbagai program yang berdampak positif (maslahat) bagi masyarakat khususnya umat islam yang kurang mampu (golongan delapan asnaf). Menurut Khasanah (2010:198), menyebutkan bahwa dengan adanya pemberdayaan ini diharapkan akan terciptanya pemahaman dan kesadaran serta bentuk sikap dan prilaku hidup individu dan kelompok menuju kemandirian.

Pendayagunaan yang efektif ialah memanfaatkan sesuai dengan sasaran dan tujuan sebagaimana dalam A-Qur'an surat Taubah ayat 60:

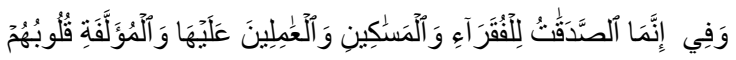

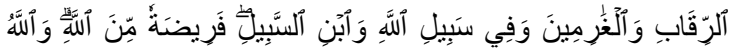

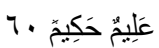

Artinya: "Sesungguhnya zakatzakat itu, hanyalah untuk orangorang fakir, orang-orang miskin, pengurus-pengurus zakat, para mu'allaf yang dibujuk hatinya, untuk (memerdekakan) budak, orang-orang yang berhutang, untuk jalan Allah dan untuk mereka yuang sedang dalam perjalanan, sebagai suatu ketetapan yang diwajibkan Allah, dan Allah Maha Mengetahui lagi Maha Bijaksana"(Depag Rl, 2002:196).

Fungsi pemberdayaan, sesungguhnya adalah upaya mewujudkan visi dan misi amil, yakni bagaimana masyarakat muzakki lebih mensyukuri atas rizki yang telah diberikan oleh Allah SWT dan mempunyai rasa solidaritas tinggi terhadap sesama muslim khususnya bagi masyarakat mustahiq. Lembaga zakat harus bisalebih inovatif dalam menyalurkan dana ZIS, dengan tetap memperhatikan dua hal; pertama, penyaluran zakat harus memberikan wawasan baru dan meningkatkan intelektual dari penerima zakat tersebut. Kedua, dalam penyaluran ZIS sudah saatnya disertai dengan pembinaan manajemen terhadap penerimannya. (Ridwan, 2004:208)

Contoh program penyaluran zakat secara produktif yang dilakukana oleh lembaga zakat yang ada di Indonesia adalah program pendidikan yaitu pemberdayaan siswa kurang mampu.

Ryandono (2008) mengatakan bahwa pemberdayaan dana zakat, infaq dan shadaqah dalam bentuk pendidikan baik formal maupun non-formal 
Siswanto, et al/Jurnal Ekonomi Syariah Teori dan Terapan Vol. 4 No. 9 September 2017: 698-712; PERAN PENDAYAGUNAAN ZAKAT, INFAQ, DAN SHADAQAH (ZIS) DALAM PEMBERDAYAAN ANAK YATIM (PURNA ASUH) PADA LEMBAGA AMIL ZAKAT YATIM MANDIRI SURABAYA

merupakan langkah yang tepat. Selain sebagai bentuk penyaluran dana zakat yang produktif, pemberdayaan dana ZIS juga dapat memotong rantai kemiskinan yang selama ini dialami oleh masyarakat khususnya bagi mereka yang berada pada kalangan ekonomi menengah kebawah. Perbaikan Sumber Daya Manusia akan membawa mereka pada tingkat kesejahteraan baik secara ekonomi ataupun secara sosial.

Pada april 2014, Pembina Yayasan Yatim Mandiri H. Nur Hidayat mengungkapkan bahwa jumlah anak yatim di Indonesia saat ini mencapai 3.2 juta dan jumlah anak yatim terbanyak berada di Nusa Tenggara Timur dan Papua. Secara rinci, anak yatim di Indonesiaa saat ini berjumlah 3.176 .642 anak dengan 157.621 anak diantaranya dari Jawa Timur.

Status anak yatim tidaklah menjamin dirinya untuk mendapatkan zakat. Dilihat dari segi terpenuhinya kebutuhan dasar bagi anak yatim, jika kebutuhan dasar anak yatim tersebut terpenuhi atau tercukupi maka tidak berhak menerima zakat. Begitu sebaliknya, jika kebutuhan dasar dari anak yatim tidak terpenuhi atau tidak tercukupi dikarenakan tidak ada yang menanggung hidupnya serta tidak memiliki harta, maka anak yatim tersebut berhak menerima zakat. Bukan status anak yatim yang membuat mereka dapat menerima zakat, melainkan karena ketidak mampuanya dalam memenuhi kebutuhan dasar hidupnya. Itulah sebabnya anak yatim masuk dalam kategori fakir atau miskin yang berhak menerima zakat (Rochim, 2013: 120).

Dalam pemberdayaan anak yatim, khususnya yang berasal dari kalangan dhuafa (lemah) adalah mendidik mereka menjadi anak yang mandiri. Dengan memberikan pelatihan dan pendampingan yang berkesinambungan.

Lembaga Amil Zakat Yatim Mandiri Surabaya merupakan sebuah lembaga sosial masyarakat yang memfokuskan pada penghimpunan dan pengelolaan dana ZISWAF (Zakat, Infaq, Shadaqah dan Wakaf) serta dana hibah lainya, baik dari perorangan, kelompok, perusahaan atau lembaga umat islam dan menyalurkanya secara profesional dengan meniti beratkan progam pendidikan untuk kemandirian anak yatim sebagai penyaluran progam unggulan. (Yatim Mandiri : 2016)

Sebagai bentuk profesionelitas dan keamanahan, yayasan Yatim Mandiri mengembangkan Lembaga Pusat Pendidikan dan Pelatihan (PUSDIKLAT) yang diperuntukan khusus untuk anakanak yatim purna asuh (anak lulusan SMU) dengan biaya gratis. Lembaga pusdiklat yatim ini bernama MEC (Mandiri Enterpreneur Center) yang mempunyai visi dan misi untuk mencetak jiwa-jiwa interpreneur pada diri anak-anak yatim yang menjadi binaanya dan bertujuan untuk menagantarkan pemuda yang produktif, berdayasaing, dan mandiri. 
Siswanto, et al/Jurnal Ekonomi Syariah Teori dan Terapan Vol. 4 No. 9 September 2017: 698-712; PERAN PENDAYAGUNAAN ZAKAT, INFAQ, DAN SHADAQAH (ZIS) DALAM PEMBERDAYAAN ANAK YATIM (PURNA ASUH) PADA LEMBAGA AMIL ZAKAT YATIM MANDIRI SURABAYA

Progam diklat di MEC dikemas dalam waktu 6 bulan hingga Maksimal 1 tahu pembinaan. Selama proses pendidikan dan pelatihan, para peserta mendapatkan tiga progam utama, yaitu: 1) pembinaan mental keagamaan, 2) pembinaan akademik adalah pembinaan yang bertujuan untuk peningkatan keahlian diberbagai bidang sesuai dengan progam studi di MEC. 3) pembinaan wirausaha dan kemandirian darisisi keuangan. Progam ini dilaksakan oleh peserta dengan cara mencari penghasilandari usahanya sendiri dengan cara bekerja dan berwirausaha.

Berdasarkan pada uraian latar belakang masalah diatas, maka rumusan masalah pada penelitian ini adalah sebagai berikut:1. Bagaimana pendayagunaan ZIS dalam pemberdayaan anak yatim melalui program MEC di Lembaga Amil Zakat Yatim Mandiri Surabaya? 2. Bagaimana perkembangan pendayagunaan ZIS dalam pemberdayaan anak yatim melalui program MEC di Lembaga Amil Zakat Yatim Mandiri Surabaya?

\section{II.LANDASAN TEORI}

\section{Pengertian Zakat}

Zakat merupakan kata dasar (masdar) dari zaka yang berarti berkah, bersih, dan baik. Zakat dari segi istilah fiqih berarti sejumlah harta tertentu yang diwajibkan Allah untuk diserahkan kepada orangorang yang berhak menerimanya (Qardhawi, 1988:34). Menurut Ryandono di dalam ZISWAF (2008:6) zakat adalah salah satu cara untuk mendistribusikan kekayaan (harta) dalam suatu perekonomian khususnya dari yang beruntung atau kaya kepada mereka yang tidak beruntung (miskin) dalam hal mencari rezeki.

Sementara secara terminologis, Sayyid Sabia mendifinisikan zakat adalah suatu predikat untuk jenis barang yang dikeluarkan manusia, sebagai hak Allah dan untuk dibagi-bagikan kepada fakir dan miskin.

\section{Landasan Hukum Zakat}

Hukum zakat adalah wajib adanya. Seorang muslim yang menunaikan perintah-Nya akan mendapat pahala, sedangkan yang meninggalkan perintahNya akan mendapatkan siksa. Kewajiban zakat telah ditetapkan di dalam Al-Qur'an dan Hadist sebagaimana yang telah disebutkan sebelumnya, serta disepakati oleh para ulama (ijma') kewajiban dalam menunaikan zakat dalam Islam wajib bagi seluruh umat-Nya yang telah memenuhi syarat dan rukun. Sebagaimana firman Allah SWTdalam surat Al-Baqarah ayat 43:

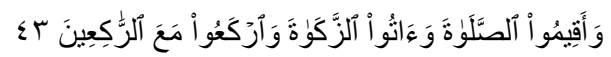
Artinya: "Dan dirikanlah shalat, tunaikanlah zakat dan ruku'lah beserta orang-orang yang ruku'." (QS. Al-Baqarah: 43) (Depag, 1993).

Hukum zakat juga telah dijelaskan dalam Undang-undang nomor 23 Tahun 2011 pasal 1 dan pasal 2 tentang zakat, yang berbunyi: zakat adalah harta yang wajib dikeluarkan oleh muslim atau badan usaha untuk diberikan kepada yang 
Siswanto, et al/Jurnal Ekonomi Syariah Teori dan Terapan Vol. 4 No. 9 September 2017: 698-712; PERAN PENDAYAGUNAAN ZAKAT, INFAQ, DAN SHADAQAH (ZIS) DALAM PEMBERDAYAAN ANAK YATIM (PURNA ASUH) PADA LEMBAGA AMIL ZAKAT YATIM MANDIRI SURABAYA

berhak menerimanya sesuai dengan syariah islam.

\section{Prinsip-prinsip Zakat}

Menurut M. A Manan dalam Ali (1988:39-40) zakat mempunyai enam prinsip, diantaranya:

1. Prinsip keyakinan keagaman (faith), adalah seorang muslim yang mebayar zakat yakin bahwa pembayaran zakat merupakan suatu bukti ketaan terhadap perintah agamanya .

2. Prinsip pemerataan (equity) dan keadilan, adalah penggambaran dari tujuan zakat yaitu membagi harta kekayaan dengan adil karena dalam suatu harta yang kita miliki terdapak hak dan kewajiban bagi orang lain.

3. Prinsip produktivitas (productivity) dan kematangan, menekankan bahwa memang wajar karena milik tertentu telah mengasilkan produk tertentu dan hasil produksi tersebut hanya dapat dipungut dan dikeluarkan setelah lewat jangka waktu satu tahun (haul).

4. Prinsip nalar (reason).

5. Prinsip kebebasan (freedom), adalah zakat hanya dikeluarkan oleh seorang muslim yang sehat baik jasmani maupun rohaninya, dan memepunyai hak untuk mengelvarkan zakat.

6. Prinsip etik (ethic) dan kewajaran, adalah zakat tidak akan diminta secara semena-mena tanpa memperhatikan akibat setelahnya.

\section{Hikmah dan Manfaat Zakat}

Zakat tidakhanya bermanfaat bagi para muzakki maupun mustahiq saja, namun zakat membewa dampak positif yang besar untuk jangka panjang bagi suatu negara secara keseluruhan jika dikelola dengan baik. Manfaat zakat ialah zakat merupakan pertolongan bagi orang-orang fakir dan orang-orang yang sangat memerlukan bantuan, zakat bisa mendorong mereka untuk bekerja dengan semangat ketika mereka mampu melakukanya dan juga bisa mendorong mereka untuk meraih kehidupan yang layak (Effendi, 2008:87).

\section{Pengertian Infaq dan Shadaqah}

Kata infaq dapat berarti mendermakan atau memberikan rizki atau menafkahkan sesuatu kepada orang lain berdasarkan rasa ikhlas dank arena Allah semata. Dari dasar Al-Qur'an, perintah infaq mengandung dua dimensi, yaitu: Pertama, Infaq diwajibkan secara bersama-sama, dan Kedua, infaq sunah yang sukarela (Suyitno, 2005:12). Allah SWT berfirman dalam Al-Qur'an surat AlBaqarah: 195, yakni:

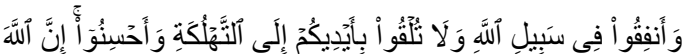

$$
\begin{aligned}
& 1900
\end{aligned}
$$

Artinya: "Dan belanjakanlah (harta bendamu) di jalan Allah, dan janganlah kamu menjatuhkan dirimu sendiri ke dalam kebinasaan, dan berbuat baiklah, 
Siswanto, et al/Jurnal Ekonomi Syariah Teori dan Terapan Vol. 4 No. 9 September 2017: 698-712; PERAN PENDAYAGUNAAN ZAKAT, INFAQ, DAN SHADAQAH (ZIS) DALAM PEMBERDAYAAN ANAK YATIM (PURNA ASUH) PADA LEMBAGA AMIL ZAKAT YATIM MANDIRI SURABAYA

karena sesungguhnya Allah menyukai orang-orang yang berbuat baik" (Q.S AlBaqarah:195).

Zakat wajib menurut bahasa juga disebut sedekah, sehingga Mawardi mengatakan, "Sedekah itu zakat dan zakat itu adalah shadaqah" berbeda nama tetapi arti sama (Qardhawi, 1999:36). Allah SWT berfirman dalamAlQur'an surat At-Taubah ayat 58:

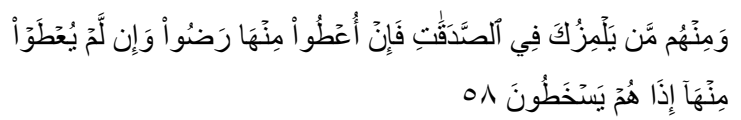
ada orang yang mencelamu tentang (sedekah) zakat; jika mereka diberi sebahagian dari padanya, mereka bersenang hati, dan jika mereka tidak diberi sebahagian dari padanya, dengan serta merta mereka menjadi marah". (Q.S AtTaubah:58)

Dalam istilah syari'at Islam, shadaqah sama dengan pengertian infaq, termasuk juga hukum dan ketentuan-ketentuannya. Sisi perbedaan hanya terletak pada bendanya. Artinya infaq berkaitan dengan materi, sedangkan shadaqah berkaitan dengan materi dan non-materi.

\section{Pengertian Pendayagunaan}

Pendayagunaan berasal dari kata daya dan guna yang berarti kemampuan mendatangkan manfaatatau hasil yang dicapai (Hasan, 2001:71).

Dalam UU No. 23 Tahun 2011 pasal 27 tentang pendayagunaan zakat yaitu:
1. Zakat dapat didayagunakan untuk usaha produktif dalam rangka penanganan fakir fiskir miskin dan peningkatan kualitas umat.

2. Pendayagunaan zakat untuk usaha produktif sebagaimana yang dimaksud pada ayat (1) dilakukan apabila kebutuhan dasar mustahiq telah terpenuhi.

3. Ketentuan lebih lanjut tentang pendayagunaan zakat untuk usaha produktif sebagaimana yang dimaksud pada pasal (1) diatur dengan peraturan menteri.

Agar pendayagunaan zakat dapat berjalan dengan baik artinya benar-benar sampai kepada orang-orang yang berhak menerimanya, maka proses pendayagunaan zakat sangat memerlukan manajemen. Laporan pendayagunaan zakat haruslah tranparansi yang perlu disampaikan kepada muzakki. Hal seperti ini, sangatlah dianggap penting guna menciptakan dan meningkatkan kepercayaan muzakki terhadap pendayagunaan zakat oleh lembaga zakat. Semua proses pendayagunaan haruslah diketahui oleh muzakki karena keberhasilah dalam pendayagunaan zakat tidak terlapas dari peran seorang muzakki.

\section{Bentuk dan Sifat Pendayagunaan Zakat}

Menurut Widodo (2001: 41), bahwa bentuk dan sifat pendayagunaan terdiri dari tiga diantaranya:

1. Hibah, zakat pada asalnya harus diberikan berupa hibah artinya 
Siswanto, et al/Jurnal Ekonomi Syariah Teori dan Terapan Vol. 4 No. 9 September 2017: 698-712; PERAN PENDAYAGUNAAN ZAKAT, INFAQ, DAN SHADAQAH (ZIS) DALAM PEMBERDAYAAN ANAK YATIM (PURNA ASUH) PADA LEMBAGA AMIL ZAKAT YATIM MANDIRI SURABAYA

tidak ada ikatan antara pengelola dengan mustahiq setelah penyerahan zakat.

2. Dana bergulir, zakat dapat diberikan berupa dana bergulir (pinjaman) oleh pengelola kepada mustahik dengan catatan harus qardul hasan, artinya tidak boleh ada kelebihan yang harus diberikan oleh mustahiq kepada pengelola ketika pengembalian pinjam tersebut. Jumlah pengembalian sama dengan jumlah yang dipinjamkan tadi.

3. Pembiayaan, penyaluran zakat oleh pengelola kepada mustahia tidak boleh dilakukan berupa pembiayaan, artinya tidak boleh ada ikatan seperti shahibul maal dengan mudharib dalam penyaluran zakat.

\section{Pengertian Pemberdayaan}

Pemberdayaan (empowerment) mengandung arti to gif power or authority to, memberikan kekuasaan atau kewenangan kepada pihak lain. Mengangkat kehidupan masyarakat miskin dan memberikan ruang gerak bagi mereka tumbuh danberkembang, mengambil keputusan-keputusan yang sesuai dengan kemampuan dan keterampilan merupakan satu bentuk dari pemberdayaan.

Adapun prosedur pemberdayaan zakat telah diatur dalam Keputusan Menteri Agama Rl Nomor 581 tahun 1999. Dalam pasal 28 disebutkan bahwa pendayagunaan hasil pengumpulan zakat untuk mustahiq dilakukan berdasarkan persyaratan, yakni: a). Hasil pendapatan dan penelitian kebenaran mustahiq delapan asnnaf khususnya fakir miskin; b). Mendahulukan orang-orang yang tidak berdaya memenuhi kebutuhan dasar secara ekonomi dan sangat memerlukan bantuan; c). Mendahulukan mustahiq dalam wilayah masing-masing. Selanjutnya, dalam pasal 29 disebutkan bahwa prosedur pendayagunaan hasil pengumpulan zakat untuk usaha produktif adalah sebagai berikut: a). Melakukan studi kelayakan; b). Menetapkan usaha produktif; c). Melakukan bimbingan dan penyuluhan; d). Mengadakan evaluasi (Rofiq, 2010: 25).

\section{Pengertian Lembaga Amil Zakat}

Lembaga Amil Zakat (LAZ) menurut Syafrudin (2012:49) adalah institusi pengelolaan zakat yang sepenuhnya dibentuk oleh masyarakat yang bergerak di bidang dakwah, pendidikan, social atau kemasyarakatan umat islam, dikukuhkan, dibina dan dilindungi oleh pemerintah.

Lembaga Amil Zakat sebagai sebuah lembaga keuangan Islam yang mempunyai fungsi dan peran dalam mengelola zakat, infaq, shadaqah atau wakaf. Menurut UU No. 23 tahun 2011 tetang pengelolaan zakat, lembaga zakat memiliki tujuan utama yaitu untuk membantu BAZNAS dalam pelaksanaan pengumpulan, pendistribusian dan pendayagunaan zakat, serta meningkatkan efektivitas dan efisiensi 
Siswanto, et al/Jurnal Ekonomi Syariah Teori dan Terapan Vol. 4 No. 9 September 2017: 698-712; PERAN PENDAYAGUNAAN ZAKAT, INFAQ, DAN SHADAQAH (ZIS) DALAM PEMBERDAYAAN ANAK YATIM (PURNA ASUH) PADA LEMBAGA AMIL ZAKAT YATIM MANDIRI SURABAYA

pelayanan dalam pengelolaan zakat; dan meningkatkan manfaat zakat untuk mewujudkan kesejahteraan masyarakat dan penanggulangan kemiskinan.

\section{Pengertian Anak Yatim}

Pengertian anak yatim dikutip dari Tafsir Al Misbah bahwasanya kata "al-yatim" terambil dari kata "yatama" yang berarti kesendirian. Karena itu, permata yang sanagt indah dan dinilai tidak ada bandinganya dinamai Ad Durrah (A) Yatimah). Bahasa menggunakan kata tersebut untuk menunjukan anak manusia yang belum dewasa yang telah ditinggal wafat baik ibu atau bapaknya atau anak binatang yang ditinggal induknya. Kematian ayah bagi seorang yang belum dewasa menjadikan kehilangan pelindung, ia seakan menjadi sendirian, sebatang kara karena itu dinami yatim.

Kedewasaan seorang anak, disamping dilihat dari kemampuan fisik untuk kawin, biasanya ditandai dengan bermimpi mengeluarkan mani dan haid untuk wanita. Hal ini diukur dengan kecerdasan, seperti yang dinyatakan oleh Allah SWT dalam QS. An-Nisa ayat 6:

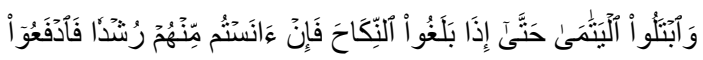

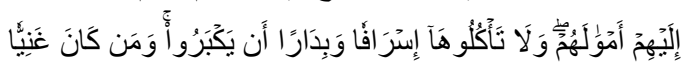

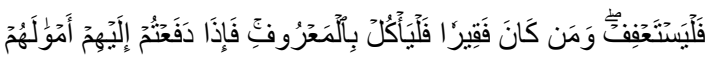

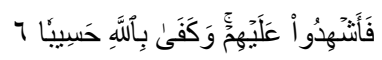

Artinya: "Dan ujilah anak yatim itu sampai mereka cukup umur untuk kawin. Kemudian jika menurut pendapatmu mereka telah cerdas (pandai memelihara harta), maka serahkanlah kepada mereka harta-hartanya. Dan janganlah kamu makan harta anak yatim lebih dari batas kepatutan dan (janganlah kamu) tergesa-gesa (membelanjakannya) sebelum mereka dewasa. Barang siapa (di antara pemelihara itu) mampu, maka hendaklah ia menahan diri (dari memakan harta anak yatim itu) dan barangsiapa yang miskin, maka bolehlah ia makan harta itu menurut yang patut. Kemudian apabila kamu menyerahkan harta kepada mereka, maka hendaklah kamu adakan saksi-saksi (tentang penyerahan itu) bagi mereka. Dan cukuplah Allah sebagai Pengawas (atas persaksian itu)"(Q.S, An-Nisa: 6).

Dari ayat tersebut dapat dikatakan bahwa faktor kecerdasan sangat penting dipertimbangkan supaya anak yatim sebelum hidup mandiri terlebih dahulu hendaklah diyakini bahwa perkembangan fisiknya telah seimbang. Tidak hanya seimbang, tetapi juga sebanding dengan perkembangan kecerdasanya (Shodiq, 2014:15).

\section{Pemberdayaan Anak Yatim}

Dalam Undang-undang Nomor 4 Tahun 1979, LN. 19979-32 tentang Kesejahteraan Anak, pasal 4 (1) menyatakan bahwa "Anak yang tidak mempunyai orang tua berhak memperoleh asuhan oleh Negara atau orang atau badan" (Tanamas. 1999:194).

Memberdayakan, meningkatkan dan memajukan anak yatim dan orang miskin yang tidak lain adalah kaum 
Siswanto, et al/Jurnal Ekonomi Syariah Teori dan Terapan Vol. 4 No. 9 September 2017: 698-712; PERAN PENDAYAGUNAAN ZAKAT, INFAQ, DAN SHADAQAH (ZIS) DALAM PEMBERDAYAAN ANAK YATIM (PURNA ASUH) PADA LEMBAGA AMIL ZAKAT YATIM MANDIRI SURABAYA

dhuafa hukumnya adalah wajib. Anak yatim dan orang miskin adalah golongan mustadh'afin yang wajib diperhatikan perbaikan dan peningkatan hidup mereka.

\section{Pengertian Pendidikan}

Pendidikan adalah usaha sadar dan terencana untuk mewujudkan suasana belajar dan proses pembelajaran agar peserta didik secara aktif mengembangkan potensi dirinya untuk memiliki kekuatan spiritual keagamaan, pengendalian diri, kepribadian,

kegerdasan, akhlaq mulia, serta kejeramplamplian yang diperlukan dirinya dan masyarakat. (UU SISDIKNAS No.20 Tahun 2003).

Ada dua jenis pendidikan yang dapat menunjang peningkatan sumber Daya Manusia, yaitu:

1. Pendidikan formal merupakan sebuah pendidikan yang berasal dan dilaksakan di lingkungan sekolah, yang diperoleh secara teratur, berurutan sesuai tinggkatanya sertaharys mengikuti syarat-syarat dan aturan-aturan yang jelas yang berlaku.

2. PPendidikan non-formal adalah jalur pendidikan yang berada diluar jalur pendidikan formal yang dapat dilaksanakan secara urut dan berjenjang.

Berdasarkan landasan teori yang telah dijelaskan, maka dapat dirancang kerangka berpikir sbagai berikut:

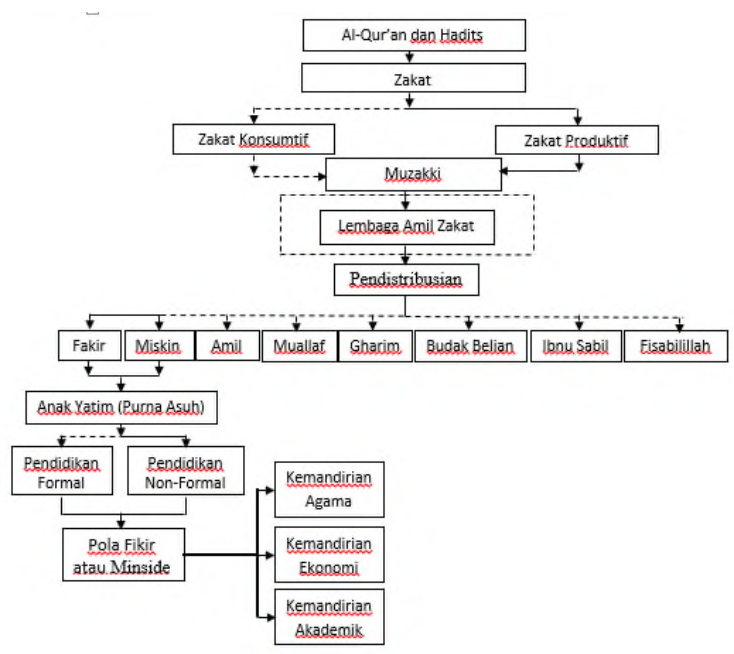

Gambar 2.1

Kerangka Berpikir

\section{METODE PENELITIAN}

\section{Pendekatan Penelitian}

Penelitian yang dilakukan dalam penelitian ini melalui pendekatan kualitatif. Pendekatan kualitatif adalah penelitian yang dimaksud untuk memahami suatu fenomena tentang apa yang dialami oleh subyek penelitian, misalnya perilaku, presepsi, motivasi, tindakan, dan lain sebagainya.

Terdapat lima strategi penelitian kuallitatif menurut Yin (2009:7), yaitu eksperimen, survey, analisis arsip, historis, dan studi kasus. Penelitian ini akan menggunakan strategi studi kasus untuk memahami masalah yang diteliti. Menurut Schramm (1971) dalam Yin (2009:17), studi kasus adalah mencoba menjelaskan keputusan-keputusan tentang mengapa studi tersebut dipilih, bagaimana 
Siswanto, et al/Jurnal Ekonomi Syariah Teori dan Terapan Vol. 4 No. 9 September 2017: 698-712; PERAN PENDAYAGUNAAN ZAKAT, INFAQ, DAN SHADAQAH (ZIS) DALAM PEMBERDAYAAN ANAK YATIM (PURNA ASUH) PADA LEMBAGA AMIL ZAKAT YATIM MANDIRI SURABAYA

mengimplementasikanya, dan apa hasilnya.

Sesuai penjelasan Yin, strategi studi kasus dipilih karena pertama, sesuai dengan pokok pertanyaan suatu penelitian berkenaan dengan how dan why. Kedua, peneliti hanya memiliki peluang yang sangat kecil atau tidak memiliki peluang sama sekali untuk mengontrol peristiwaperistiwa yang akan diselidiki. Ketiga, terdapat proposisi atau arahan dan fokus penelitian yang dibangun diawal proses penelitian.

\section{Ruang Lingkup Penelitian}

Penelitian dalam skripsi ini dilakukan untuk menjawab rumusan masalah penelitian yaitu Bagaimana pendayagunaan ZIS dalam pemberdayaan anak yatim melalui program MEC di Lembaga Amil Zakat Yatim Mandiri Surabaya dan Bagaimana perkembangan pendayagunaan ZIS dalam pemberdayaan anak yatim melalui program MEC di Lembaga Amil Zakat Yatim Mandiri Surabaya.

Penelitian difokuskan pada peran dan manfaat pendayagunaan dana ZIS yang dilakukan oleh Lembaga Amil Zakat "Yatim Mandiri" kepada anak yatim di Surabaya.Ruang lingkup penelitian, terbatas pada aktivitas Yatim Mandiri dalam melakukan penyaluran ZIS di bidang pemberdayaan ekonomi.Obyek dalam penelitian ini adalah lembaga zakat yang menghimpun, dan mengelola ZIS, serta menyalurkannya di bidang pemberdayaan ekonomi.

\section{Jenis dan Sumber Data}

1. Data Primer

Data primer dalam penelitian ini berasal dari key informan (informan kunci). Dalam hal ini yang dimaksud informan kunci, yaitu:

a. Manajer dan karyawan yatim mandiri yang memahami tentang progam pemberdayaan ekonomi khususnya program MEC.

b. Pimpinan atau pengajar kampus kemandirian yang mengikuti program MEC (Mandiri Entepreneur Center).

c. Mahasiswa yang mengikuti program MEC. Dalam penelitian ini jumlah mahasiswa yang menjadi informan adalah tiga orang.

\section{Data Sekunder}

Data pendukung dalam penelitian ini berasal dari buku-buku terkai dengan zakat, infaq dan shadaqah, pendayagunaan, anak yatim dan pemberdayaan; hasil-hasil penelitian yang berwujud buku, laporan, jurnal, makalah, internet, dan kajian pustaka yang berkaitan dengan permasalahan; serta dokumen yang diperoleh dari Yatim Mandiri dan Kampus Kemandirian yang berupa dokumen-dokumen administrative yang berkaitan dengan penelitian.

\section{Prosedur Pengumpulan Data}

Mengacu pada tiga prinsip pengumpulan data yang dikemukakan oleh Yin, penelitian ini menggunakan teknik pengumpulan data sebagi berikut:

a. Persiapan awal 
Siswanto, et al/Jurnal Ekonomi Syariah Teori dan Terapan Vol. 4 No. 9 September 2017: 698-712; PERAN PENDAYAGUNAAN ZAKAT, INFAQ, DAN SHADAQAH (ZIS) DALAM PEMBERDAYAAN ANAK YATIM (PURNA ASUH) PADA LEMBAGA AMIL ZAKAT YATIM MANDIRI SURABAYA

Pada tahap ini, peneliti mengurus surat izin penelitian skripsi secara formal pada bagian akademik Fakultas Ekonomi dan Bisnis (FEB) UNAIR sebagai pelengkap untuk memasuki lembaga zakat yang diteliti.

b. Proses memasuki lokasi atau obyek penelitian

Pada tahab ini, peneliti segera menemui bagian manajer lembaga zakat dengan membawa surat izin penelitian secara formal dari FEB UNAIR sebagai pelengkap.

C. Saat dilokasi obyek penelitian

Peneliti menjelaskan maksud dan tuujuan penelitian kepada manajer lembaga zakat dan kampus kemandirian kemudian wawancara dengan pihak manajer dan pimpinan atau kepala kampus kemandirian.

d. Saat pengumpulan data

Peneliti mendapatkan data dari wawancara pihak manajer lembaga zakat sebagai obyek penelitian.pengambilan data dan wawancara dilakukan secara terbuka dan dengan pertanyaan yang terus berkembang setiap peneliti dating ke lokasi dimana obyek penelitian itu berada, tetapi tetap terfokus dan mengarah pada topic penelitian.

\section{Teknik Keabsahan Data}

Pada penelitian ini, teknik yang digunakan untuk pengujian keabsahan data adalah triangulasi sumber data. Sumber dan mengecek baik derajat kerpecayaan suatu data yang telah diperoleh melalui beberapa sumber.
Dalam peneltian ini triangulasi sumber dilakukan dengan jalan membandingkan hasil wawancara dengan isi suatu dokumen yang berkaitan guna memperoleh keterkaitan antar data.

\section{Teknis Analisis}

Penelitian ini menggunakan pendekatan analisis data yang dikemukakan oleh Yin (2009:133) yakni terdapat tiga teknik: Penjodohan pola, Pembuatan penjelasan, dan Analisis deret waktu. Pembahasan dilakukan dengan membahas program yang digunakan untuk penyaluran dana ZIS oleh LAZ Yatim Mandiri yang disalurkan kepada anak yatim purna asuh (dhuafa) dengan fokus penelitian kepada program pendidikan yang diberikan kepada anak yatim purna asuh untuk mencapai pada kemandirian.

\section{Hasil dan Pembahasan}

Dalam kegiatan pendistribusian dan zakat, infaq dan shadaqah, LAZ Yatim Mandiri Surabaya menyusun terlebih dahulu anggaran pendistribusian setiap program dan skala prioritas pendistribusian. Dana ZIS yang didapat dari para donator disalurkan melalui program-program hasil dari temuantemuan di masyarakat.

Dari hasil Wawancara diketahui bahwa dana ZIS yang berhasil dikumpulkan LAZ Yatim Mandiri didistribusikan kepada mustahia khususnya anak yatim dengan mekanisme survey dan seleksi.

Pendistribusian dana ZIS yang dilakukan LAZ Yatim Mandiri terbagi dalam dua betuk. Pertama, 
Siswanto, et al/Jurnal Ekonomi Syariah Teori dan Terapan Vol. 4 No. 9 September 2017: 698-712; PERAN PENDAYAGUNAAN ZAKAT, INFAQ, DAN SHADAQAH (ZIS) DALAM PEMBERDAYAAN ANAK YATIM (PURNA ASUH) PADA LEMBAGA AMIL ZAKAT YATIM MANDIRI SURABAYA

pendistribusian dana ZIS dalam bentuk konsumtif. Pendistribusian ini diberikan kepada mustahiq secara langsung dalam bentuk bantuan sesaat. Diantaranya disalurkan untuk bantuan konsumtif bagi anak yatim yang berprestasi, bantuan untuk korban bencana alam, bantuan pada bulan Ramadan, pemberian alatalat sekolah dan lain-lain. Kedua, pendistribusian dana ZIS dalam bentuk produktif. Pendistribusian ini diberikan dalam bentuk modal usaha. Misalnya untuk pendistribusian secara produktif dalam bentuk modal usaha LAZ Yatim Mandiri memberdayakan bunda yatim melalui program pelatihan dan pendampingan kewirausahaan. Tujuan dari penyaluran secara produktif berupa bantuan modal usaha untuk mengembangkan kemampuan mustahiq agar dapat menghasilkan sesuatu yang akan membantu meningkatkan penghasilan dan kesejahteraan mustahiq. Sebagaimana pendapat Ryandono (2008:50) yang menyatakan bahwa zakat merupakan instrument untuk mendistribusikan kekayaan antar pelaku ekonomi sehingga kesenjangan Antara kaya dengan miskin pun semakin mmenyempit.

\section{LAZ Yatim Mandiri dalam} mendistribusikan dana ZIS melalui program pendidikan merupakan langkah tepat dalam meningkatkan kualitas umat (anak yatim). Melavi program MEC dimana didalamnya terdapat pendidikan formal dan non formal dengan tujuan untuk merubah minside dalam mencapai kemandirian. Dimana didalam program MEC selain memberikan pemberdayaan dalam bidang pendidikan, juga memberikan pelatihan, pendampingan, serta pembinaan moral, agama, dan sosial. Pendayagunaan dana ZIS di LAZ Yatim Mandiri ditujukan untuk membangun dan merupah mindsite/pola fikir mustahiq (anak yatim) yang hanya berfikir menggunakan secara konsumtif.

Pendayagunaan dana ZIS di LAZ Yatim Mandiri khususnya untuk anak yatim meliputi bidang pendidikan. Pendidikan merupakan sebagian dari ilmu pengetahuan memiliki bagian terpenting dalam peningkatan kualitas Sumber Daya Manusia (SDM). Salah satu tujuan dari pendayagunaan ZIS dalam bidang pendidikan yang disalurkan untuk membantu mustahiq (anak yatim) yaitu agar terciptanya pendidikan yang layak dan menningkat secara kualitas. Manusia yang berkualitas dapat membantu sektor pembangunan bagi suatu negara.

Program Mandiri Enterpreneur Center (MEC) di LAZ Yatim Mandiri merupakan program unggulan yang menggunakan dana ZIS dalam memberdayakan anak yatim (purna asuh) yang kuurang mampu. Pendidikan yang diberikan berupa pengajaran didalam kelas dengan menggunaka metode pembelajara yang di sesuaikan dengan keadaan dunia kerja dan usaha. Pendampingan sosial dan moral diberikan diluar kelas. Pelatihan dan monitoring diberikan dalam pengembangan usaha. Jadi bukan hanya pemberdayaan dalam pendidikan 
Siswanto, et al/Jurnal Ekonomi Syariah Teori dan Terapan Vol. 4 No. 9 September 2017: 698-712; PERAN PENDAYAGUNAAN ZAKAT, INFAQ, DAN SHADAQAH (ZIS) DALAM PEMBERDAYAAN ANAK YATIM (PURNA ASUH) PADA LEMBAGA AMIL ZAKAT YATIM MANDIRI SURABAYA

melainkan juga pemberdayaan dalam sprirituan, moral, dan sosial.

Pendistribusin dana ZIS pada program ini merupakan bentuk investasi jangka panjang yakni merupakan bentuk investasi Sumber Daya Manusia (SDM). Dengan tujuan pemberdayaan anak yatim (purna asuh) dapat memutus rantai kemiskinan melalui pengurangan pengangguran. Pendayagunaan dana ZIS dengan maksimal sangat memberikan pengarus yang besar untuk perekonommian suatu Negara.

Yang mendasari LAZ Yatim Mandiri dalam memberdayakan anak yatim adalah melihat kesiapan mereka untuk mandiri. Jika hanya melihat dari fisik mungkin mereka siap, akan tetapi jika melihat dari segi kedewasaan dan kecerdasan anak yatim mungkin mereka kurang siap terlebih dari segi mental dan keterampilan. Oleh karena itu, LAZ Yatim Mandiri mencoba untuk menyeimbangkan antara pertumbuhan fisik, kedewasaan, dan kecerdasan sebelum mereka benar-benar dan mampu untuk menjadi pribadi yang mandiri.

Melalui program MEC, LAZ Yatim Mandiri telah memberdayakan anak yatim yang tidak mampu (dhuafa). Adapun hasil dari pemberdayaan tersebut adalah anak yatim sebagai penerima dana bantuan ZIS tersebut telah mandiri dari segi: Pertama, kemandirian akademik yaitu anak yatim (duafa) mendapat ilmu pengetahuan sesuai dengan bidang yang diambil dan ditekuni. Dengan bimbingan dan arahan dari pengajar atau dosen mereka dapat mengembangkan ilmu yang telah dipelajari dalam bentuk usaha dan berwirausaha. Kemandirian akademik yang diterapkan melalui program MEC mengacu pada dunia usaha dan dapat langsung diterapkan dilapangan. Kedua, kemandirian agama atau spiritual yakni anak yatim (dhuafa) mendapatkan bimbingan akhlaq dan akhidah, bimbingan baca al-Qur'an, dan bimbingan ibadah. Semua pembinaan tersebut mereka dapatkan ketika mengikuti program MEC, karena selama mengikuti program tersebut mereka tingal di asrama disertai dengan pendamping asrama. Ketiga, kemandirian kewirausahaan yaitu anak yatim (dhuafa) mendapatkan pelatihan langsung dalam merencanakan dan melaksanakan langsung kegiatan berwirausaha. Kemandirian ini tidak lepas dari nama program itu sendiri, dimana nama entrepreneur benar-benar diterapkan selama proses pendidikan dan pelatihan tersebut.

Indikator keberhasilan program Mandiri Enterpreneur center (MEC) adalah lulusan yang mampu bersaing dalam hal bekerja ataupun berwirausaha dengan tidak meninggalkan kewajiban beragama dan bermasyarakat.

\section{Simpulan}

Program Mandiri Enterpreneur Center adalah bentuk pendayagunaan zakat, infaq, dan shadaqah dalam 
Siswanto, et al/Jurnal Ekonomi Syariah Teori dan Terapan Vol. 4 No. 9 September 2017: 698-712; PERAN PENDAYAGUNAAN ZAKAT, INFAQ, DAN SHADAQAH (ZIS) DALAM PEMBERDAYAAN ANAK YATIM (PURNA ASUH) PADA LEMBAGA AMIL ZAKAT YATIM MANDIRI SURABAYA

pemberdayaan anak yatim melalui pendidikan dan pelatihan. Pendidikan yang lebih mengarah kepada pengetahuan dasar akan suatu bidang tertentu. Tujuan dari pendayagunaan zakat, infaq, dan shadaqah dalam pemberdayaan anak yatim adalah untuk kemandirian. Kemandirian secara akademik, kemandirian secara agama, dan kemandirian secara ekonomi.

Perkembangan pendayagunaan zakat, infaq, dan shadaqah tidak dilihat dari seberapa besar jumlah anak yatim yang diberdayakan melainkan dilihat dari output setelah mengikuti program Mandiri Enterpreneur Center (MEC). Indikator keberhasilan program Mandiri Enterpreneur adalah lulusan yang mapu bersaing di dunia usaha dan dunia kerja dengan tidak meninggalkan kewajiban sebagai seorang muslim.

\section{Daftar Pustaka}

Ali, Daud.2006.Sistem Ekonomi Islam: Zakat dan Wakaf. Jakarta: UI Press.

Departemen Agama RI. 2002. Al-Qur'an dan Terjemahannya. Jakarta: Darus Sunnah

Depdiknas. 2003. Undang-Undang Nomor 20 tahun 2003. Tentang Sistem Pendidikan Nasional.

Effendi, Agus dan Bahruddin Fananny. 2008. Zakat : KAJIAN BERBAGAI MAZHAB. BANDUNG. PT Remaja Rosdakarya

Hasan, M. Ali. 2008. Zakat dan Infaq: Salah Satu Solusi Mengatasi Problema Sosial di Indonesia. Jakarta: Putra Grafika.
Khasanah, Umrotul. 2010. Manajemen

Zakat Modern. Malang: UIN Maliki Press. Muhammad Joni dan Zulchaina $Z$. Tanamas. 1999. Aspek Hukum Perlindungan Anak dalam Perspektif Konvensi Hak Anak,. Bandung: PT. Citra Aditya Bakti, Cet. I, hlm. 194

Pusat Bahasa dan Budaya. 2005. Tentang penghimpunan zakat.

Qardhawi, Yusuf. 1988. Figh Zakat. Bogor: Pustaka Litera Nusantara.

-----, Yusuf. 1999. HUKUM ZAKAT (Penerjemah :Harun Salman, Hafidhuddin Didin dan Hasanuddin). Bandung. Mizan dan PT Pustaka Litera AntarNusa. Cetakan ke-5.

Ridwan, Muhammad. 2004. Manajemen Baitul Maal Wa Tamwil. Yogyakarta: UII Press.

Rochim, Abdul. 2013. Gelombang

Ekonomi Zakat. Jakarta: Dompet

Dhuafa.

Rofiq, Ahmad. 2010. Kompilasi Zakat. Semarang: Balai penelitian dan pengembangan agama semarang

Ryandono, Muhammad Nafik Hadi. 2008.

Ekonomi ZISWAQ (Zakat, Infaq, Shadaqah dan Waqaf). Surabaya. IFDI dan Cenforis.

Shodiq, Ja'far. 2014. Santunilah Anak Yatim. Yogyakarta: Lafal.

Suyitno. 2005. Anatomi Figh Zakat. Yogyakarta: Pustaka Pelajar.

Syafrudin, Arif.2012. Redistribusi Hak Orang Miskin Melalui Zakat Produktif. Jurnal Ekonomi Islam, III, 1 (6):39-59 
Siswanto, et al/Jurnal Ekonomi Syariah Teori dan Terapan Vol. 4 No. 9 September 2017: 698-712; PERAN PENDAYAGUNAAN ZAKAT, INFAQ, DAN SHADAQAH (ZIS) DALAM PEMBERDAYAAN ANAK YATIM (PURNA ASUH) PADA LEMBAGA AMIL ZAKAT YATIM MANDIRI SURABAYA

Undang-undang Republik Indonesia Nomor 23 tahun 2011 Tentang Pengelolaan Zakat.

Widodo, Hertanto \& Teten Kustiawan. 2001. Akuntansi dan Manajemen Keuangan untuk Organisasi Pengelola Zakat. Jakarta: Institut Manajemen Zakat.

Yin, R. K. 2009. Studi Kasus \& Metode. Jakarta: Raja Grafindo Persada. http://www.bps.co.id. BPS. 2010. Profil Kemiskinan Di Indonesia. Hari Senin 02 jam 10.30 WIB.

http://yatimmandiriby.blogspot.com, tentang yayasan yatim mandiri. Hari Senin 02 Agustus 2016, jam 11.00 WIB. 